I6 a 18 de outubro de 2019 - Campinas | Brasil

\title{
A DISTRIBUIÇÃO ESPACIAL DA INDÚSTRIA E SUA CONTRIBUIÇÃO PARA O CRESCIMENTO URBANO DA REGIÃO METROPOLITANA DE CAMPINAS
}

\author{
Lucas Pinto Seixas*, Prof. Dr. Lindon F. Matias
}

\begin{abstract}
Resumo
O processo de industrialização foi uma importante causa do crescimento da cidade de Campinas e da formação de sua Região Metropolitana. Esta pesquisa se propôs a analisar a atual configuração espacial da indústria na Região Metropolitana de Campinas, que é resultante de processos históricos, econômicos e sociais, e sua contribuição para o crescimento urbano, buscando construir uma base de dados georreferenciados sobre a disposição geográfica das indústrias. Assim, o presente trabalho busca trazer contribuições para o tema com uma metodologia baseada em reflexões teóricas em concomitância com o uso de geotecnologias.
\end{abstract}

\section{Palavras-chave: \\ Campinas, Configuração Espacial, Industrialização}

\section{Introdução}

A análise da configuração espacial da indústria, inserida no modo de acumulação capitalista, permite considerações acerca das dinâmicas da geografia econômica e urbana à medida que sua relação com 0 território se dá num contexto de conflito de interesses sociais com agentes hegemônicos, que condicionam o processo de (re)produção do espaço objetivando o acúmulo de capital.

O processo de industrialização na Região Metropolitana de Campinas (RMC) aconteceu de modo intenso durante a segunda metade do século $X X$, em um momento de desconcentração da atividade industrial no estado de São Paulo, que se encontrava, anteriormente, concentrada na capital (SELINGARDI-SAMPAIO, 2009).

O trabalho teve como objetivo contribuir para 0 conhecimento do processo de (re)produção do espaço geográfico na RMC, objetivando entender a relação do processo de espacialização das unidades produtivas com a expansão urbana, bem como reforçar a possibilidade de uso de geotecnologias como importante instrumento para a aquisição de dados espacializados, de interesse para as análises em geografia econômica.

\section{Resultados e Discussão}

A localização da atividade industrial se materializa na RMC de forma articulada com objetos e ações sociais e econômicas. Tanto Sposito (2007), ao propor o conceito de eixo de desenvolvimento, como Selingardi-Sampaio (2009), ao discutir sobre a formação industrial do Estado de São Paulo, são fundamentais para a compreensão da localização industrial na região.

Destaca-se também que o principal subsídio para entender a configuração industrial na RMC foi 0 mapeamento das unidades industriais por meio de vetorização on screen, utilizando o software ArcGIS 10.6, em escala 1:10.000, a partir de imagens do Google Earth. Como resultado, tem-se intensa relação das unidades industriais com as rodovias. Um dado revelador é que $97,5 \%$ da área industrial está localizada a menos de $5 \mathrm{~km}$ de distância de uma das rodovias principais. A rodovia Anhanguera (SP-330) se destaca com uma mancha industrial densa a partir de Campinas, passando pelos municípios de Hortolândia, Sumaré, Nova Odessa e Americana.
Os municípios de Indaiatuba e Paulínia (principalmente por conta da Replan), ao longo das rodovias Santos Dummont (SP-075) e Prof. Zeferino Vaz (SP-332), respectivamente, também possuem importantes áreas industriais.

É muito relevante para a discussão destacar que a RMC conta com uma consolidada infraestrutura de transportes e comunicação.

$\mathrm{Na}$ Tabela 1 constam resultados das análises realizadas através de procedimentos no ArcGIS 10.6 a fim de obter dados quantitativos acerca das edificações industriais e da mancha urbana na RMC, com intuito de fundamentar as reflexões teóricas.

Tabela 1. Área Urbana e Industrial

\begin{tabular}{|l|c|c|}
\hline & $\begin{array}{l}\text { Área da mancha } \\
\text { urbana }\left(\mathrm{km}^{2}\right)\end{array}$ & $\begin{array}{l}\text { Área da mancha } \\
\text { industrial }{ }^{2}\left(\mathrm{~km}^{2}\right)\end{array}$ \\
\hline RMC & 880 & 44,01 \\
\hline Campinas & 255 & 6,30 \\
\hline
\end{tabular}

Fonte: ${ }^{1}$ GeoGet, 2019; ${ }^{2}$ elaboração própria com base em Geoget, 2019

\section{Conclusões}

Principalmente ao longo da segunda metade do século $X X$ e no início do século $X X I$, à luz das reestruturações do modo de produção em escala global, percebe-se que a (re)produção capitalista do espaço atuou de forma desigual na RMC. Esse processo foi responsável por uma configuração que concentra as edificações industriais em alguns municípios e próximos às rodovias principais em forte relação com o avanço da mancha urbana.

\section{Agradecimentos}

Ao Serviço de Apoio ao Estudante (SAE/Unicamp) e à Fundação de Amparo à Pesquisa do Estado de São Paulo (Fapesp) pelo financiamento desta pesquisa referente ao processo 2018/15919-3.

SELINGARDI-SAMPAIO, Silvia. Indústria e Território em São Paulo: A estruturação do Multicomplexo Territorial Industrial Paulista: 1950 2005. Campinas: Alínea, 2009.

SPOSITO, Eliseu. Reestruturação produtiva e urbana no estado de São Paulo. Scripta Nova. Revista Electrónica de Geografía y Ciencias Sociales. Barcelona, v.XI, n.245 p. 69, 2007 